\title{
THE INFLUENCE OF TEAMWORK AS AN INTERNAL MARKETING \\ FACTOR ON THE QUALITY OF THE SERVICE OF INSURANCE COMPANIES IN SERBIA'S AGRICULTURAL SECTOR
}

\author{
Ivan Piljan ${ }^{1}$, Zoran Simonović2, Nikola Curčić3 \\ *Corresponding authorE-mail: zoki@medianis.net
}

\begin{abstract}
A R T I C L E I N F O
Original Article

Received: 26 February 2020

Accepted: 03 March 2020

doi:10.5937/ekoPolj2001189P

UDC 338.43:368]:005.743
\end{abstract}

Keywords:

teamwork, market success, internal marketing, common goal, agriculture

JEL: G22, Q14

\begin{abstract}
A B S T R A C T
The subject matter of this paper is the analysis of the quality of the services and the sustainability of the business operations of insurance companies in the agricultural sector in the Republic of Serbia, depending on the teamwork concept. Teamwork belongs to the internal marketing factors in companies' business doing. Teams should have a common goal which the members may only achieve through joint work and a combination of the knowledge and abilities pertaining to different areas. Client satisfaction is a teamwork efficiency measure. Apart from a large number of satisfied users, a large number of new insurance programs innovated from year to year and offering its users an increasingly big range of possible types of insurance are also the indicators of the successful business doing of insurance companies in the agricultural sector. The research study was done on a suitable sample of 250 respondents, employed in 10 insurance companies.
\end{abstract}

(C) 2020 EA. All rights reserved.

\section{Introduction}

Contemporary life brings man many risks, which on their part bring big consequences. In order for the consequences that have occurred to be facilitated, there is an increasingly frequent need in people for using insurance. Insurance companies have devised different business systems to accompany needs for insurance, offering their insured clients different insurance services, giving them a compensation for the incurred damage,

1 Ivan Piljan, $\mathrm{PhD}$, Associate Professor, Faculty of Business Economics and Entrepreneurship, Belgrade, +381 (0) 11 2762-194, e-mail: ivan.piljan@vspep.edu.rs, ORCID ID (https:// orcid.org/0000-0002-3502-9060)

2 Zoran Simonović, PhD, Research associate, Institute of Agricultural Economics, Belgrade, Volgina St. No.15, Phone: + 381 (0) 11697 2858, e-mail: zoki@medianis.net, ORCID ID (https://orcid.org/0000-0002-2769-6867).

3 Nikola Ćurčić, PhD, Research associate, Institute of Agricultural Economics, Belgrade, Volgina St. No.15, Phone: + 381 (0) 11697 2858, e-mail: nikolavcurcic@yahoo.com, ORCID ID (https://orcid.org/0000-0003-3375-2690). 
which was incurred due to an unexpected event. Within their business operations, insurance companies offer their clients insurance against different risks.

Not all of that would be possible if insurance companies did not have good business associates, who solve problems and newly-emerged specific situations from one client to another on a team basis. Team cooperation within an insurance company is one of the factors for the successful business doing of any insurance. In that sense, we observed teamwork as a factor of internal marketing in Serbia's agriculture.

The team concept of work has been existing for hundreds of years now, throughout centuries, and has its place in different environments and cultures. Man has always known that there are so many things he cannot do on his own. It is important to highlight the fact that teamwork is very important for the highest management authorities inside an organization, as well as managers at all levels and workers as a whole. In the case of a lack of teamwork at any level, that leads to limiting the organization's efficiency. If teamwork is well-devised, it will lead to the improvement of the overall business operations of the organization and the achievement of the basic goal of every business policy of the enterprise.

Team members may achieve much more through joint work than they would otherwise be able to accomplish by themselves, using their potentials to the greatest possible extent. This joint work, framed by a common mission, is teamwork.

\section{Materials and methods}

In this paper, the methods that best reflect the character of the analysis given in the title of the paper were used. In researching the quality of the services rendered by insurance companies in the context of the significance of teamwork as a factor of internal marketing in the agriculture of Serbia, quantitative methods of economic analysis were dominant. In the first place, those are the various texts, statistical data and literature sources related to the application of teamwork. During the research, the analysis of the content of the secondary data sources was also used. The secondary data, information about teamwork were taken from the relevant literature. It should be mentioned that numerous and significant Internet information was also used. Empirical research in the efficiency of the application of teamwork in insurance companies is especially highlighted.

The contribution of this paper reflects in the review and analysis of the efficiency of the application of teamwork as a factor of internal marketing in insurance companies in the Republic of Serbia. The fact that there is a need for insurance companies to dedicate to teamwork is indicated. Only in that manner is it possible for them to be more efficient by applying teamwork in the Republic of Serbia, which we believe is confirmed by this paper.

The paper demonstrates the fact that well-organized teamwork as a factor of internal marketing is an advantage, which on its part means that it should be treated as such, especially bearing in mind the contemporary understanding of the development of 
insurance companies. As can be seen from the wording of the paper, the result of this research study is perceiving the full role and full significance of teamwork as a potential model for a better organization of insurance companies.

A special contribution is made in the part of the research work dealt with based on the empirical research and related to teamwork. In that sense, the authors have concluded that the quality of services and the successfulness of the business doing of insurance companies depend on the emotional and intellectual statuses of team members. That will contribute to the buyer's choice of an appropriate product to a significant extent.

In this paper, an effort was made by the authors to present the reader with an insight into the current state of the matters in the insurance companies that provide insurances to the agrarian sector. They consider it necessary today, when it is necessary to encourage agricultural producers to insure their estates, as well as their mechanization.

\section{Results and Discussions}

\section{Service Quality in the Context of Teamwork Significance}

The quality of a service is considered to be the key determinant of the achieved level of client satisfaction, where a higher level of the service quality leads to a greater client satisfaction degree.

Quality is the key element of service value since it enables an organization to position itself in the market and its greater market share based on buyer and employee mutual satisfaction. Service quality reflects through the level of the satisfaction of users' needs and demands and compliance with growing needs and expectations. (Stepanov, et al., 2017).

The notion "team" implies an organized group of people dedicatedly working on the achievement of the organization's common goals. Everybody is responsible for that goal, everybody does the best they can to reach it, achieve it, try to overcome their own expectations as well. Of special significance is the fact that all members of a team understand each other and respect one another. (Petkovic, et al., 2012).

This century has brought with itself numerous changes when speaking about the implementation of set plans and goals of organizations throughout the world, not only here, in our country. In this time, any business doing deprived of teamwork seems to be unimaginable. In the $21^{\text {st }}$ century, a "team" has an enormous influence on the overall success of an organization, simultaneously also implying one of certainly the best manners of work organization. (Piljan, et al., 2015).

The characteristics of modern organizations' unstable external environment exert a significant impact on finding out new ways of business doing, aimed at attracting new clients, achieving and maintaining competitiveness and sustainable development. (Ze, et al., 2018). The last economic crisis, accompanied by political, cultural, social and moral pressures, led to new conditions for organizations and many of them were unable to survive. (Berber, et al., 2019). 
The following reasons are highlighted as the most significant:

1. the positive experiences and the positive effects of teamwork achieved so far;

2. the ability to quickly adapt to newly-emerged situations;

3. the attachment of team members, the team and the management and the team and the organization as a whole to one another and loyalty between them;

4. increased motivation;

5. improved communication and improved interpersonal relationships;

6. a rational use of human resources in the organization;

7. a reduction in the costs of manufacturing, etc. (Ovčina, 2015).

Teamwork and internal interaction are considered as one of the factors of companies' internal marketing. In addition to the internal marketing factors, the following can also be listed: workers' competence and skill, employee satisfaction, the dissemination of marketing information among employees, participation in decision-making, as well as service culture. Hereby, internal marketing can be defined as: "a planned effort using a marketing-like approach to overcome organizational resistance to change and to align, motivate and inter functionally co-ordinate and integrate employees towards the effective implementation of corporate and functional strategies in order to deliver customer satisfaction through a process of creating motivated and customer orientated employees. (Ahmed, et al., 2003). The role of internal marketing in the context of service quality can be formulated as "a means of creating customer-conscious frontline employees as a means to ensuring high service quality for customers of service organizations." (Amangala, et al., 2013).

\section{Workgroup and Team - Similarities and Differences}

A workgroup and a team are the notions that are mainly always identified with one another. These are similar, but not the same notions. A workgroup is the notion implying a structure of a kind, which has its specific features, not only being a mere set, pool of individual persons. A workgroup implies their joint work.

A workgroup is primarily formed with the aim of exchanging information and making decisions in order to help every single member to do the job more effectively and more efficiently. (Božović, et al., 2014).

When speaking about teams, the fact that the manufacturing of goods of social significance is the main reason why teams exist in small workgroups in organizations is highlighted as their main characteristic. When comparing these two notions, we must bear in mind the fact that all teams in the world are certain groups, but not all groups are, nor can all groups be, teams. Some group of people may, but does not have to, be a team, but a team must be one, fully functional, active and organized group of people that has set a common goal. It is only then that ever member individually aspires to achieve that goal, which is the main characteristic of every team. 
Differently from a group, team members have complementary types of knowledge and skills that they direct towards their common goal, whose achievement they are considered to be responsible for - both individually and collectively. Teamwork creates a synergy, because the result of the work of the team members does only represent a mere sum of the individual results of the work done by each team member, as is the case with a group. The effects of teamwork depend both on individual and on joint work, whereas the effects of groupwork exclusively depend on the individual performance of each group member. A difference is also evident in the degree of their autonomy. Groups may, but do not have to be autonomous in their acting to have the work done, whereas teams enjoy a high degree of such autonomy in work and decision-making. It is characteristic of groups to promulgate decision by voting, whereas inside teams, solutions are, as a rule, reached through a consensus (Pavičić, 2012).

Contrary to individuals belonging to a group, all those team members have complementary knowledge and skills by means of which they aspire to achieve some common goal, whose implementation they are considered to be responsible for, both individually and collectively. It is significant to all members that their work should be successful and that it should generate positive results. What is the result of their cooperation is not only the summing-up of their individual work results, but the accomplishments resulting from such teamwork also depend both on individual and on collective action inside the team, whereas the effects of the work performed by a group exclusively depend on the personal performance of each single member of the group.

Workgroups always have a formal leader, who has a certain power and certain rights towards other workers. Work teams are the groups whose members intensively work on a certain joint task (achieving a goal) by using their positive synergy, the individual and joint responsibilities and additional skills through a coordinated effort. (Radivojević, 2011).

The sources of occupational stress (stressors) may be individual - arising from a work role; at a group level - caused by the dynamics and conduct of managers inside the group; or organizational - arising from the characteristic of the organization. (Katić, et al., 2019).

Now it is possible to reach a conclusion, according to which team work implies every activity performed by individuals within a given group, which is intentionally organized, with a certain goal, and work distribution inside it is founded on different experts' cooperation-based work, trust, helping each other and competitiveness.

\section{Factors Influencing Teamwork Efficiency}

Organizations' very essence implies an incessant search for a new way that would help and make it easier for them to cope with competition, the requirements imposed by innovations in work. The quality of teamwork is founded on the outcome which team members aspire to while performing their work and on the satisfaction of all those working on that team as well. 
Satisfaction is founded on the possibility of working in a team-like manner to satisfy the personal needs of the members, thus increasing loyalty to the team for that purpose. The factors such as types of teams, the structure, composition, then homogeneity (or heterogeneity) of the team with respect to the team members' years of age, sex, skills, knowledge and attitudes influence the internal processes in teams that ultimately determine the satisfaction of the team members and the final result. (Malić, 2014).

Ever since the labor process exists, there is no record of the fact that one of teamwork models in business operations has ever been more significant for the business doing of the organization itself than it is the case in the $21^{\text {st }}$ century. All potential reasons for which teams are increasingly frequently applied in business doing arise from that.

One of the most significant factors for a team's successful work and functioning is the determination of a work strategy. A team must have clearly defined goals, and in compliance with them - a clearly developed strategy and concept of work. A strategy defines the issues concerning the work of the team, internal relationships on the team, the relationship of the team towards the environment, and so forth. Therefore, it is desirable that, particularly so at the beginning of their work, team members should make a work plan and strategy. (Vasić, 2014).

The final result is determined through qualitative and quantitative achievements made by the team, defined through team goals. The foundations of satisfaction rest on the possibility of work in a team-like manner to satisfy the personal needs of the team members, thus increasing their loyalty to the team for that purpose. The factors such as types of teams, the structure, composition, homogeneity, or heterogeneity of the team with respect to the team members' maturity, sex, skills, types of knowledge and attitudes have an influence on the internal processes in teams, which ultimately determine the satisfaction of the team members and the final result. Efficiency is important because it represents a determinant of an organization's success and pertains to satisfying the organizational valley. Efficiency is a degree of the connectedness between the real and the wanted results. (Lunau, et al., 2018).

Teams should have a common goal, which the members of the team can only achieve through their joint work and a combination of the knowledge and capabilities from within different areas. That is how each member will have an opportunity to make their own contribution to problem solving. Client satisfaction is a teamwork efficiency measure.

Feedback on joint successes, or failures, the knowledge of the joint result, as well as the rewarding system which values the team, not its individual members, encourages motivation for joint work.

Communication is a two-way process between the message sender and the message recipient, where the message recipient must not only receive a message, but understand it as well. Successful communication implies that a piece of information has accurately been received in respect of the content and meaning intended by the sender. (Pavić, 2011). 
Their manager, who sends feedback on the results of the work performed by the team as a whole, plays an important role in that. He also stimulates communication amongst teams, thus influencing the development of a competitive spirit amongst them. Processes inside teams, such as a conflict, group norm development, cohesion and members' beliefs in the efficiency of their own team also exert a big influence on team efficiency.

Successful communication is the basis for good and quality teamwork. As a joint form of work performed by a greater or smaller number of people, teamwork depends to a great extent on the manner of the dissemination of information between the members of the team. If the information dissemination system is adequate, the team members' efficiency is greater. Inadequately conveyed information may lead to a collapse in teamwork and distancing from the set goals. In order for team members to be able to successfully communicate, they need to master the basic skills pertaining to the communicating area. (Hadžipešić, et al., 2012).

\section{Team Roles as a Factor for Employees' Emotional and Intellectual Statuses}

As an answer to the question: how it is possible that some teams perform successful work while some do not, numerous theoreticians have observed organizations so as to give a quality answer to this question. Their research studies have shown that teams work much more successfully when companies combine roles in them. In order for a team to work successfully, simultaneously achieving envious results, it should be equally focused on the tasks entrusted to the team and the emotional and intellectual statuses of its members as well.

Apart from a joint approach and mutual role complementation, the complementarity of knowledge and skills and dedication to the mutual purpose of action, which gives teamwork an identity, teamwork must also be characterized by a joint responsibility, both the feeling of the responsibility of each team member towards the team and of the team towards each single member of the team. Teamwork can be said to be the key component of productivity, efficiency, job satisfaction and results. (Piljan, et al., 2018).

The composition of any team in a company, as well as their tasks, depend in a large degree on the form of profession and the goal to be pursued by the team. The role of psychology is also significant. Various groups of cognitive psychologists and economists have presented a large body of evidence over the last few years indicating that the gap between psychology and economics has narrowed significantly. (Krstić, Radivojevič, 2019)

Teamwork has become a necessary element in the successful business doing of any organization. Every kind of teamwork is important for the development of the personnel potential of an organization. Independently of the problems and obstacles that may appear in teamwork, results are far better and decisions are more adequate if several people work on a single task. All of them are based and focused on the benefit of the team. The development of a team is a dynamic process. The majority of teams incessantly undergo changes. In order for their team to be as efficient as possible, it must become a team in the first place. (Kossek, et al., 2014). 
The success of business organizations and institutions is strongly connected with their ability to establish mutual work and to efficiently manage teamwork. A new synergy requires different teams and groups working together on the creation of a new corporate responsibility through different kinds of activities, such as permanent learning, an increase in the innovativeness of the enterprise, and problem-solving skills. (Zubanov, et al., 2017).

Members' mood ranges from excitement to depression. Every stage is equally valuable as a part of the planned journey towards team maturity, whereas only that at which a team is insufficiently developed or at which a team stays too long is bad. (Krstić, Krstić, 2016) The first team development stage should indicate what is yet to be realized, whereas the last stage indicates what has been achieved of what was planned, what has been done more than envisaged, what has not been achieved, and so on.

\section{Insurance Companies in the Republic of Serbia}

The insurance market significantly influences the development of the economy of every country and is the important factor of the stability of the financial sector. The insurance market in Serbia is undeveloped and, according to the development degree, it ranks considerably below the average of the European Union member countries. (Ćurčić, et al., 2019).

In the Serbian life insurance market, the leading role is played by life insurance products, that is, insurance with a precisely defined payment period, life insurance, death insurance and mixed life insurance. (Vojinović et al., 2018)

At the end of the year 2018, there were 20 insurance companies operating in the Republic of Serbia, which is one company less than in the previous year. A total of 16 companies are exclusively engaged in insurance jobs, whereas there are four companies engaged in reinsurance jobs. Of the companies engaged in insurance jobs, there are four companies exclusively engaged in life insurance, and a total of six companies exclusively engaged in nonlife insurance and six in both life and nonlife insurance.

Multinational companies generally have more developed and more efficient management practice than local enterprises. (Poor, et al., 2017).

Observed as per the capital ownership structure, out of the 20 insurance companies at the end of the year 2018, a total of 15 were in a majority foreign ownership. The insurance companies in a majority foreign ownership at the end of 2018 recorded a prevalent share in the life insurance premium (90.7\%), nonlife insurance premium $(62.0 \%)$, the total assets $(77.6 \%)$, as well as the number of employees (68.4\%). (NBS, 2019).

Sustainable development goals have the potential to accelerate innovations and economic growth. Sustainable development ambitious goals will, however, require new models of cooperation between companies, sectors, states and regions. (Radukić, et al., 2019). 
The forthcoming digitalization era, which equally affects both the banking sector and the insurance industry sector, will bring with itself new conveniences primarily for clients, then for insurance companies as well. Clients will come to all needed services more quickly and in a simpler way, whereas insurance companies will be making significant savings, in connection with which their profitability will also be greater. Of course, all this should be accompanied by an adequate legal regulation, which will enable the free flow of capital and services. (Piljan, et al., 2016).

In 2018, the insurance companies achieved a total premium in the amount of 99.9 billion dinars (i.e. 845 million euros or 966 million dollars), which represents a nominal increase and a real increase of $7.3 \%$ and $5.2 \%$, respectively. (NBS, 2019).

In the agricultural sector, insurance has a big potential to develop on the Serbian market, because only $9-10 \%$ of arable agricultural areas are now insured. Because of increasingly frequent weather hazards, a need has emerged for new insurance types, too, which is simultaneously a new business opportunity for insurance companies as well.(https://www.svijetosiguranja.eu/poljoprivredno-osiguranje-u-srbiji/)

\section{Analysis of Service Quality Depending on the Teamwork Concept in Insurance Companies}

The final section of an IMRAD paper. Its purpose is to fit the results from the current study into the preexisting fabric of knowledge. The important points will be expressed as conclusions. This should explore the significance of the results of the work, not repeat them. A combined Results and Discussion section is often appropriate. Avoid extensive citations and discussion of published literature.

The research study was carried out on a suitable sample of 250 respondents out of 10 insurance companies in the Republic of Serbia (Generali, GRAWE, Millennium, SAVA Nonlife Insurance, SAVA Life Insurance, Danube, AMS, Triglav, DDOR, WIENER STADTISCHE). A survey questionnaire in the form of a Likert Scale for measuring attitudes, specially constructed for the given research study, was used to collect the data. The defined Likert Scale has five gradation levels: (1) I don't agree, not at all; (2) I mainly don't agree; (3) I neither agree nor disagree - I have no clear attitude; (4) I mainly agree, and (5) I absolutely agree. The survey questionnaire had four parts, with the offered attitudes, namely:

1. Team Synergy in Insurance Companies;

2. The Quality of the Work Done by Team Members of Insurance Companies;

3. Innovativeness in the Business Operations of Insurance Companies' Teams; and

4. The Quality of Business Operations Inside Insurance Companies’ Teams. 


\section{Problem and Subject Matter of the Conducted Research Study}

The problem of this research study is: the efficiency of the application of teamwork in insurance companies.

In compliance with the established problem of the research study, we focused our interest on discovering what the relationship between and among teams in a company is like. The subject matter of the mentioned research study is established in compliance with the defined problem. As the subject matter of this research study, we shall mention the degree of the efficiency of the application of teamwork in insurance companies.

\section{Goal and Tasks of the Research Study}

An increase in the number of insurance companies in the Republic of Serbia, their expansion, their greater placement of services in the market, the expansion of their capacities, as well as the complexity of their organization - they all indicate that having teams in place in business operations has become the necessary link in the chain of their business doing. Teamwork is, among other things, necessary in companies for the reason of the fact that insurance companies have experienced an abrupt expansion in the past decade. In order for them to operate in parallel with the needs of the contemporary client, the expanding of their own business operations also increases the number of the necessary teams so as to make their business doing as successful as possible and generate positive results. Accordingly, the goal of our research study is defined as follows: to determine the significance of team business doing in insurance companies.

The following research tasks are formed out of the set goal:

1. to determine whether there is synergy in teams or not;

2. to determine whether team members have appropriate skills in business operations;

3. to determine how high the degree of teams' innovative achievements is; and

4. to determine whether the teams operating in the company perform the duties entrusted

5. to them in a quality manner.

\section{Hypotheses of the Research Study}

The hypotheses of the research study were determined according to the set goal and tasks. The main hypothesis was formed according to the set goal, and the ancillary hypotheses were formed according to the set tasks. The main hypothesis reads as follows: Service quality is assumed to depend on the emotional and intellectual statuses of the business team and is of great significance to the successful business doing of insurance companies.

The ancillary hypotheses read as follows: 1. Synergy is assumed to be existent in teams; 2. Team members are assumed to have appropriate skills in business doing; 3 . The 
degree of teams' innovative achievements is assumed to be high; and 4. The teams operating in the company are assumed to be performing the duties they are entrusted with in a quality manner.

\section{Interpretation of the Research Results}

The analysis of the results will be carried out individually as per each question, in the way how they appeared in the survey questionnaire. The questions are presented in the form of groups, or sets. The first group pertains to the first research task with the aim of confirming/rejecting the set hypothesis. The degree of synergy in the insurance companies' teams should be determined, i.e. whether synergy itself does exist in teams or not should be determined. The term synergy implies the feeling of belongingness to the team. The answers we received are presented graphically and textually.

Figure 1. Synergy in the insurance companies' teams

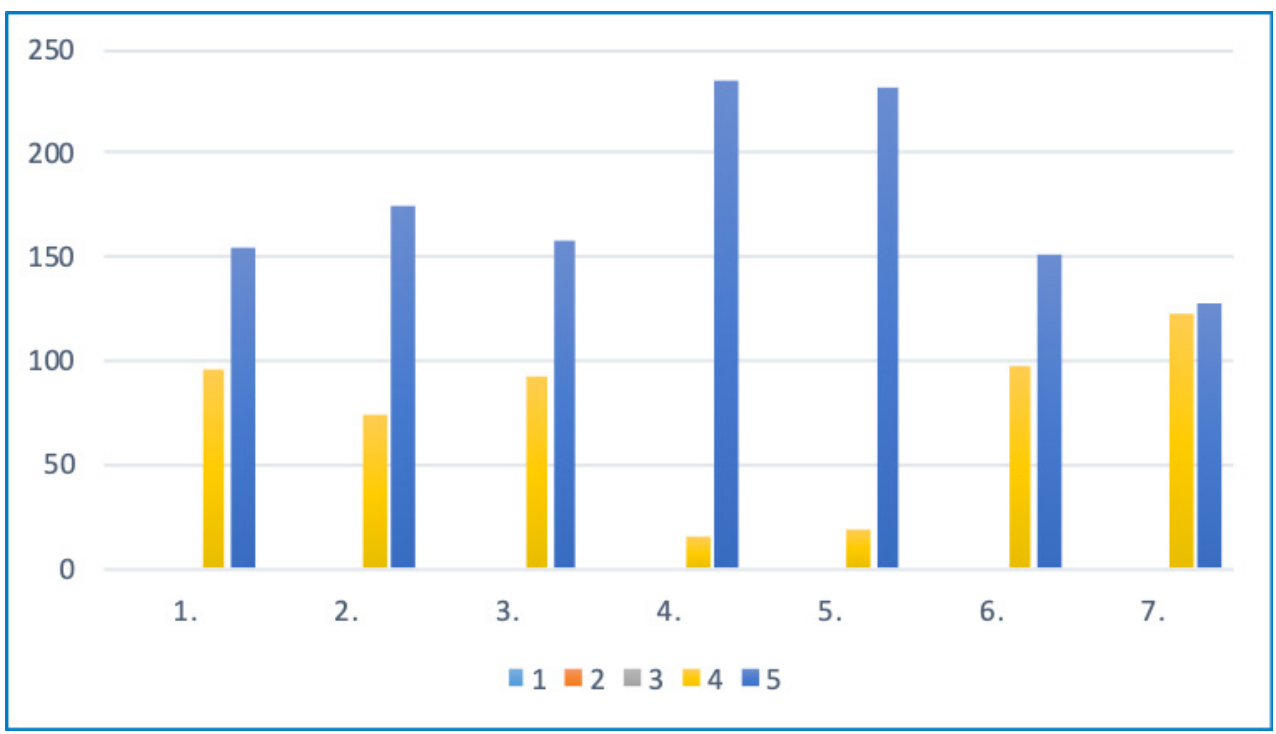

Offered assertions: 1. Belongingness to the team in which I work is clearly defined; 2 . The needs for teamwork are clearly determined; 3 . We all efficiently communicate inside the team; 4. I consider myself to be a very responsible team member; 5 . I am very satisfied with the team I do business in; 6 . The goal that the team aspires to is concretized and clearly determined; 7 . All members of the team in which I do business do their best to achieve the team goal and do business efficiently.

\section{Source: Authors' calculations}

When speaking about syne.rgy in the teams, we observe that all the respondents assert that they feel they are very valuable members of their respective teams. This is of exceptionally great importance both to the team and to the overall business operations of the insurance companies. It is important for companies to provide their employees with favorable work conditions so that they could feel comfortable. The very feeling of 
comfortableness at work leads to positive results. The needs for teamwork are clearly determined, and the members inside the team establish normal communication. In order for a team to be efficient and make progress, it is important that the connection between the team goals and the company goals should be established. Only in this way will the team achievements reach their highest level.

The second group of the offered assertions, out of which assertions the respondents should select that which is the most competent to describe the current state, pertain to the skills of the team members, the quality of each team member individually, the level of the qualification(s) of the team members for the quality performance of the tasks they are entrusted with, all aimed at achieving planned results.

Figure 2. The quality of the work performed by the insurance companies' team members

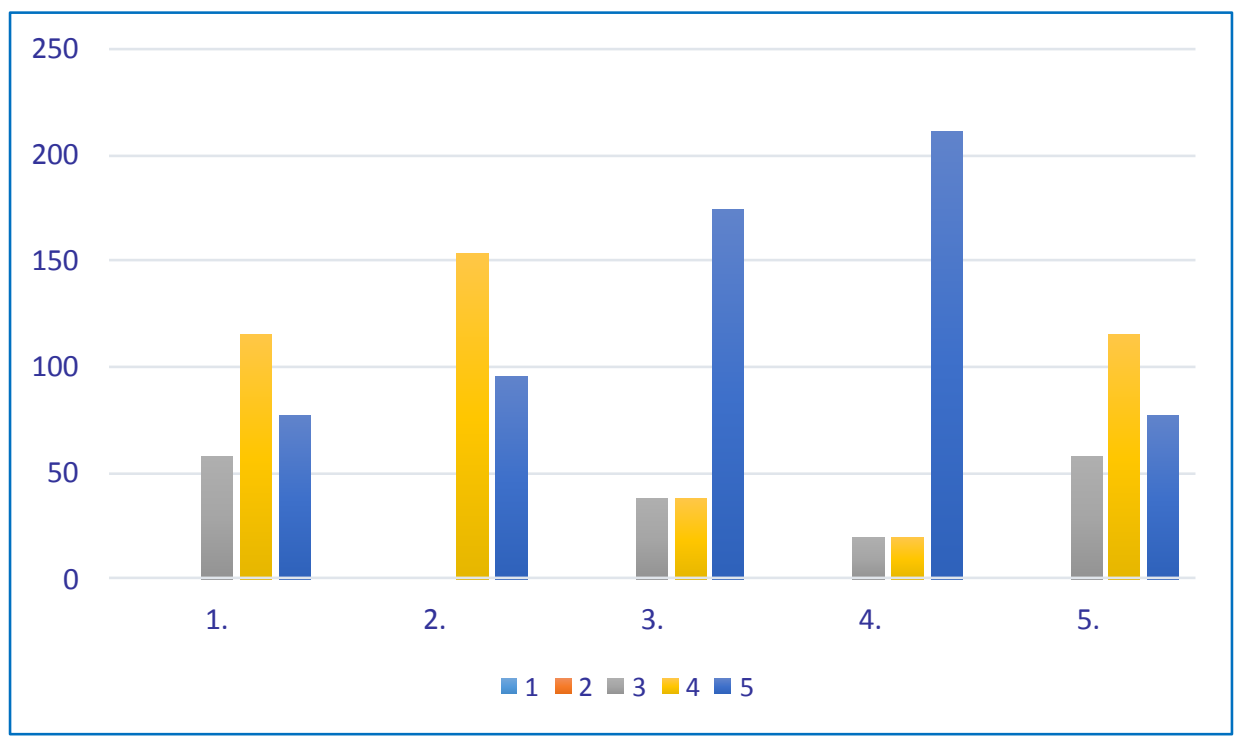

Offered assertions: 1. The team members are interested in testing new forms of work inside the team; 2 . The team's innovative activities are highly appreciated by the company, and the same are also rewarded as often as not; 3 . All problems inside the team are solved promptly and timely; 4. Solving problems inside the team is a new motivation for making progress, learning and development; 5. All team members very often autonomously make proposals for the introduction of innovations in work.

\section{Source: Authors' calculations}

When speaking about the quality of the work done by the team members individually, what must be noticed is that the members professionally perform the duties they have been entrusted with so that their team could be successful and in order to achieve the set goal. The fact that a company recognizes not only its clients' roles, but also its employees' roles, is of exceptional significance. According to the answers given by the employees who took part in the research study, it is possible to see that the companies aspire to the 
constant improvement of the capabilities of their employees both through professional training courses and through their additional education which will enable the members to constantly be knowledgeable of innovative approaches in work. The companies recognize their employees' possibilities and affinities, so they accordingly also organize additional training courses for the members on the teams. In order to realize the very goal to which a team may be aspiring at a given moment, it is important that all team members should fulfill the duties entrusted to them, i.e. what they are required to do. Team members are ready to learn more, to advance, to primarily work on themselves, which later also reflects on the quality of the business operations of the company itself. All team members adapt to innovations in the business process very quickly.

The third set of the questions pertain to innovativeness in business doing.

Figure 3. Innovativeness in the business operations of the insurance companies' teams

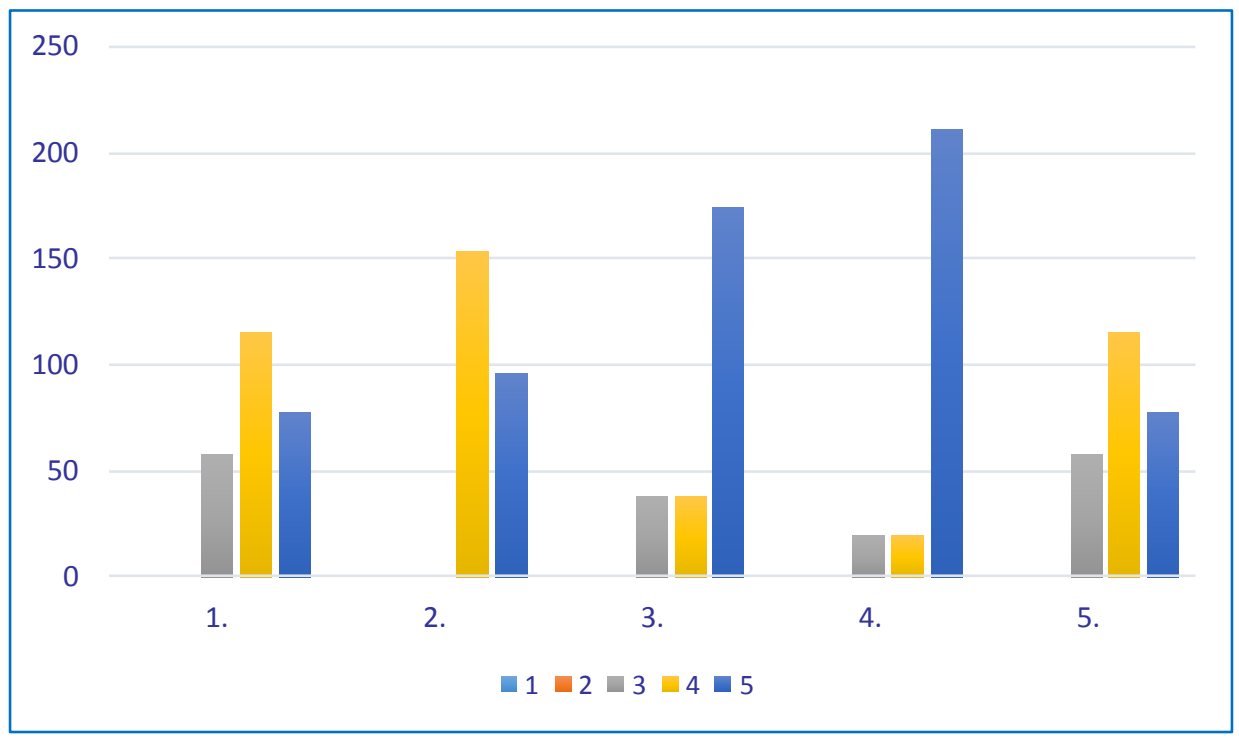

Offered assertions: 1. The team members are interested in testing new forms of work inside the team; 2 . The team's innovative activities are highly appreciated by the company, and the same are also rewarded as often as not; 3 . All problems inside the team are solved promptly and timely; 4. Solving problems inside the team is a new motivation for making progress, learning and development; 5 . All team members very often autonomously make proposals for the introduction of innovations in work.

\section{Source: Authors' calculations}

When speaking about innovations in companies' business operations, it is first of all needed to emphasize the fact that the introduction of innovations in work is of very great importance. We have come to the conclusion that the team members in the companies are very motivated to apply innovations in their business operations. Innovations are mainly appreciated and rewarded, which can only be an incentive for employees in 
their future work. The employees consider problem solving to be learning and making progress independently. The team members frequently make proposals on their own for the introduction of certain innovative ways to achieve the team goal, and they also accept the innovation that the companies consider as suitable for business doing and the quality performance of the set task.

The fourth group of questions pertain to the quality of business operations.

Figure 4. The quality of business operations inside the insurance companies' teams

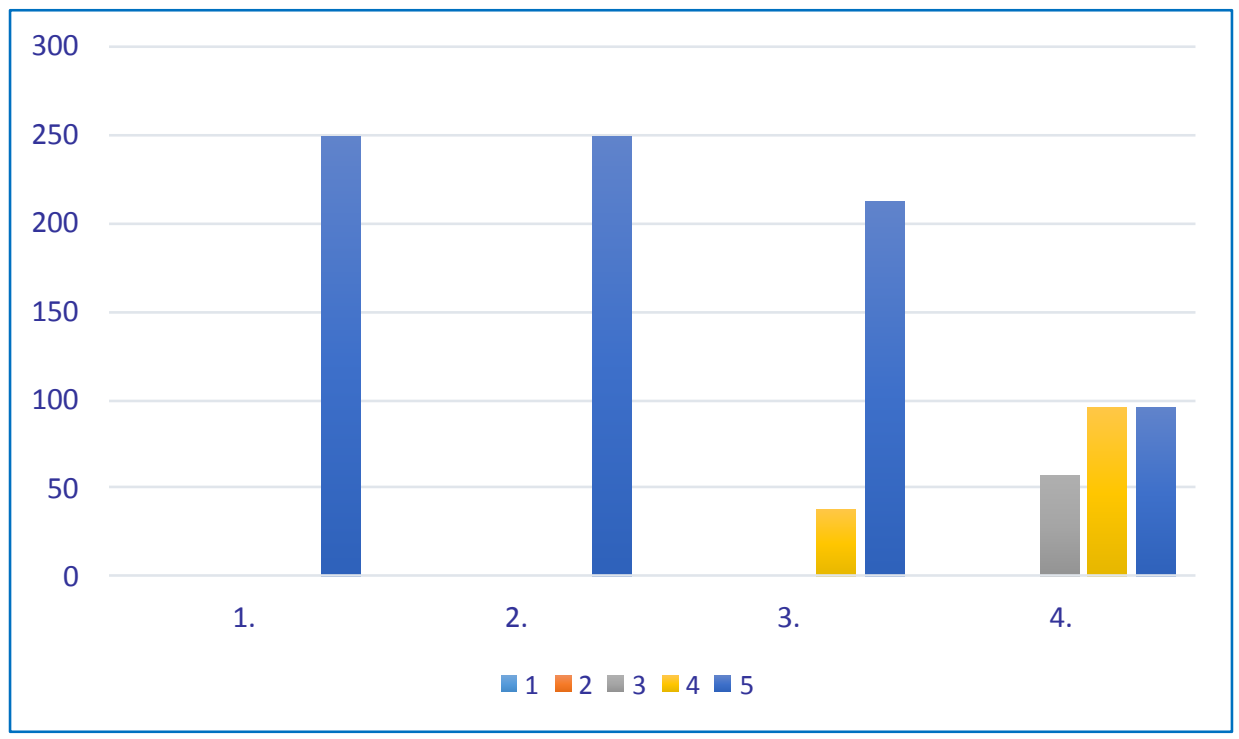

Offered assertions: 1. The members are sensitive to client needs; 2 . The goal of business operations on the team is defined and clearly precisely presented; 3 . The work performed by all the team members is regularly monitored, assessed, corrected and rewarded; 4. Clients' potential complaints are considered and timely reacted to by the team members.

\section{Source: Authors' calculations}

In this group of questions, we obtain the data about the quality of business operations inside the insurance companies. The team members who were included in the research sample are made familiar with their clients' needs, appetites and wishes, have empathy with them, and the business doing standards of a team are clearly defined through the very goal the team aspires to. The fact that the employees regularly receive feedback on their work is very important. By doing so, the employee, not only the client, is also put in the focus of interest. Their work is monitored, assessed, corrected and rewarded. By doing so, employees are also additionally motivated to continue that work pace, potentially correct particularities related to their work so that the team could make even greater progress and position itself high on the ladder of its company's teams. 


\section{Conclusions}

According to the research study we conducted, we came to the conclusion that the quality of the services and the successfulness of the business operations of insurance companies in the agricultural sector depend on team members' emotional and intellectual statuses, which will to a significant extent contribute to the selection of the buyer for a particular product.

Team efficiency also reflects on the overall business operations of the insurance companies. The results we obtained through conducting an anonymous survey of the 250 employees of the insurance companies we presented graphically and textually. As a condensed conclusion on this phenomenon, we state the following:

All the team members have their clearly defined roles, and inside the team, the members establish normal communication. Therefore, the research hypothesis reading: Synergy is assumed to be existent in teams has been confirmed.

When speaking about the quality of the work performed by the team members individually, what must be noticed is the fact that the members professionally perform the duties entrusted to them so that the team could be successful and in order to achieve the set goal. Through the answers about the quality of the work done by the team members, yet another ancillary hypothesis has been confirmed, namely the one reading: Team members are assumed to have appropriate skills in business doing.

In the insurance companies, the team members are very motivated to apply innovations in their business operations. Innovations are mainly appreciated and rewarded, which can only be an incentive for the employees in their future work. By confirming that there are innovative activities in the business doing of the insurance companies' teams, the ancillary hypothesis reading: The degree of teams' innovative achievements is assumed to be high has also been confirmed.

In the fourth group of questions, we generate the data about the quality of the business operations inside the insurance companies. The team members who made up the research sample are familiar with their clients' needs, appetites and wishes, have empathy with them, and the business doing standards of a team are clearly defined through the very goal aspired to by the team. By analyzing the fourth group of the respondents' answers, we came to the conclusion that the last ancillary hypothesis reading: The teams operating in the company are assumed to be performing the duties they are entrusted with in a quality manner has also been confirmed.

Through the answers to the posed questions, we have come to the conclusion that the hypotheses we set have been confirmed.

We have also made a reference to the factors that influence team efficiency, and we have also checked the manners in which this efficiency is measured. Team work is evidently needed in the cases of large and complex tasks requiring different capabilities and types of knowledge or consisting of a series of the operations that must be carried 
out simultaneously. It is difficult to imagine organizations based on their employees' individual work and rigid management. The management of an organization is more than ever before interested in maximally using up their employees' knowledge, which is realized within the frameworks of teamwork, where the personnel resources and the potentials for the achievement of the organization's goals are united. All the members consider that it is significant for their work to be successful and generate positive results. The result of teamwork depends both on the individual work done by every member individually and on their joint work, whereas the effects of the work done by a group exclusively depend on the personal performance of every single member of the group. In order for a team to efficiently work, the team needs to be equally focused on the task and on the social-emotional conduct of its members. So, it is important to conclude that teams in insurance companies are very efficient. Insurance companies have people oriented towards their respective jobs. Team members achieve good results, but they are motivated and ready to learn more about their job. By maintaining a state like this in continuity, every team will be successful, and team members will be satisfied, which further leads to such a situation in which the company itself will only be going from one strength to another in the future. All of the foregoing should also be highlighted in the context of internal marketing, one of whose factors is teamwork, which has been presented in the paper in more detail.

\section{Acknowledgements}

Article as research is financed by the Ministry of Education, Science and Technological Development of the Republic of Serbia.

\section{Conflict of interests}

The authors declare no conflict of interest.

\section{References}

1. Amangala, T., \& Amangala, E. (2013). Effects of internal marketing and its components on organisational level customer orientation: An empirical analysis. European Journal of Business and Management, 5(8), 64-73.

2. Ahmed, P. K., Rafiq, M., \& Saad, N. M. (2003). Internal marketing and the mediating role of organisational competencies. European Journal of Marketing, $37,(9), 1221-1241$.

3. Agricultural insurance in Serbia, Retrieved from https://www.svijetosiguranja.eu/ poljoprivredno-osiguranje-u-srbiji/ (October 2, 2019)

4. Berber, N., Slavić, A., Miletić, S., Simonović, Z., \& Aleksić, M. (2019). A Survey on Relationship between Leadership Styles and Leadership Outcomes in the Banking Sector in Serbia. Acta Polytechnica Hungarica, 16(7), 167-184.

5. Bozovic, J., Saracevic, M., \& Milošević, A. (2014). Insurance Distribution Channels in Serbia. Ekonomika, 60(4), 105-116. 
6. Ćurčić, N., Piljan, I., \& Simonović, Z. (2019). Marketing concept in insurance companies. Ekonomika, 65(3), 21-33.

7. Hadži Pešić, M.; Brajović Car, K.; Mitrović, (2012). M. Communication Model in the Approach to Personal Personal Adaptations; Personality and Educational Work; Faculty of Philosophy: Niš, Serbia, 108-116.

8. Katić, I., Knežević, T., Berber, N., Ivanišević, A., \& Leber, M. (2019). The impact of stress on life, working, and management styles: How to make an organization healthier?. Sustainability, 11(15), 4026.

9. Krstić, M., \& Radivojević, V. (2019). Behavioral economics: elements and application. Vojno delo, 6, 319-333.

10. Krstić, B., \& Krstić, M. (2016). Rational Choice Theory and Social Research. Sociology, 58 (4), 598-611.

11. Kossek, E. E., Hammer, L. B., Kelly, E. L., \& Moen, P. (2014). Designing work, family \& health organizational change initiatives. Organizational dynamics, 43(1), 43-53.

12. Lunau, T., Wahrendorf, M., Müller, A., Wright, B., \& Dragano, N. (2018). Do resources buffer the prospective association of psychosocial work stress with depression? Longitudinal evidence from ageing workers. Scandinavian journal of work, environment \& health, 44(2), 183-191.

13. Malić, D. (2014). Successful team communication and types of teams (Doctoral dissertation, Polytechnic of Međimurje in Čakovec. Management of tourism and sport.).

14. NBS. (2019). Reportfor 2018. Insurance sector in the Republic of Serbia. Belgrade.

15. Ovčina,A. (2015). Organization and organizational change. Faculty of Management and Business Economics. Travnik.

16. Pavić, Ž. (2011) Ethics and business communications. University Singidunum. Belgrade.

17. Pavičić, G. (2012). Teams and teamwork. Faculty of Economics and Management. Doboj.

18. Petković, M.; Jovanović, M. (2012). Organizational behavior. Megatrend University of Applied Sciences. Belgrade.

19. Piljan, I.; Cogoljević, D.; Piljan, T. (2015). The role of insurance companies in the financial market. International Review, 1-2, 94-102.

20. Piljan I.; Piljan, T.; Cogoljević, D. (2016). The application of e-business in the distribution of insurance services. Trends in business. 4(2), 55-65.

21. Piljan, I.; Cogoljević, D.; Piljan, T. (2018). Insurance. Faculty of Business Economics and Entrepreneurship. Belgrade. 
22. Poór, J., Slavić, A., \& Berber, N. (2017). The challenges of HRM activities at MNC subsidiaries in CEE region: Based on CEEIRT 2015/16 research. Annals of the Faculty of Economics in Subotica, (38), 109-120.

23. Radivojević, A. (2011). Teams and teamwork in the organization. CCD. Belgrade.

24. Radukić, S., Petrović-Ranđelović, M., \& Kostić, Z. (2019). Sustainabilitybased goals and and achieved results in Western Balkan countries. Economics of Sustainable Development, 3(1), 9-18.

25. Stepanov, S., Stepanov, N., \& Vukotić, N. (2017). Quality management of hospitality services. Economics, 63(1), 83-96.

26. Vasić, M. (2014). Teams and teamwork. Institute of Dystrophy, Banja Luka.

27. Vojinović, Ž., Zelenović, V., \& Savai, A. (2018). Investment unit-linked life insurance: Comparison of the Serbian and Hungarian markets. Annals of the Faculty of Economics in Subotica, (39), 171-185.

28. Ze, Y., Abbas, H., Hussain, T., \& Jiao, H. (2018). Analyzing the differentiation strategies of big companies competing with each other. Strategic Management, 23(3), 25-37.

29. Zubanov, V., Katić, I., Grubić Nešić, L., \& Berber, N. (2017). The role ofmanagement teams in business success: Evidence from Serbia. Engineering economics, 28(1), 68-78. 